\title{
1 Manganese concentrations in Scottish groundwater
}

3 Sally C. Homoncik ${ }^{\mathrm{a}}$, Alan M. MacDonald ${ }^{\mathrm{b} *}$, Kate V. Heal ${ }^{\mathrm{c}}$, Brighid É. Ó Dochartaigh ${ }^{\mathrm{b}}$,

4 Bryne T. Ngwenya ${ }^{\mathrm{d}}$.

${ }^{\mathrm{a}}$ MNV Consulting Ltd., Spinningdale, Stirling Road, Callander, Perthshire, FK17 8LE, UK

(Formerly The University of Edinburgh/British Geological Survey)

${ }^{\mathrm{b}}$ British Geological Survey, Murchison House, West Mains Road, Edinburgh, EH9 3LA, UK

${ }^{\mathrm{c}}$ The University of Edinburgh, School of GeoSciences, Crew Building, West Mains Road,

Edinburgh, EH9 3JN, UK

d The University of Edinburgh, School of GeoSciences, Grant Institute, West Mains Road,

Edinburgh, EH9 3JW, UK

*Corresponding author: email: amm@bgs.ac.uk, tel: + 44131667 1000; fax: +44 131668

2683

\section{Abstract}

Groundwater is increasingly being used for public and private water supplies in Scotland, but there is growing evidence that manganese $(\mathrm{Mn})$ concentrations in many groundwater supplies exceed the national drinking water limit of $0.05 \mathrm{mg} \mathrm{l}^{-1}$. This study examines the extent and magnitude of high Mn concentrations in groundwater in Scotland and investigates the factors controlling Mn concentrations. A dataset containing 475 high quality groundwater samples was compiled using new data from Baseline Scotland supplemented with additional high quality data where available. Concentrations ranged up to $1.9 \mathrm{mg} \mathrm{l}^{-1}$; median $\mathrm{Mn}$ concentration was $0.013 \mathrm{mg} \mathrm{l}^{-1}$ with $25^{\text {th }}$ and $75^{\text {th }}$ percentiles 0.0014 and $0.072 \mathrm{mg} \mathrm{l}^{-1}$ respectively. The Scottish drinking water limit $\left(0.05 \mathrm{mgl}^{-1}\right)$ was exceeded for $30 \%$ of samples and the WHO health guideline $\left(0.4 \mathrm{mg} \mathrm{l}^{-1}\right)$ by $9 \%$; concentrations were highest in the Carboniferous sedimentary aquifer in central Scotland, the Devonian sedimentary aquifer of Morayshire, and superficial aquifers. Further analysis using 137 samples from the Devonian aquifers indicated strong redox and $\mathrm{pH}$ controls $(\mathrm{pH}$, Eh and dissolved oxygen accounted for $58 \%$ of variance in $\mathrm{Mn}$ concentrations). In addition, an independent relationship between $\mathrm{Fe}$ and Mn was observed, suggesting that Fe behaviour in groundwater may affect Mn solubility. Given the redox status and $\mathrm{pH}$ of Scottish groundwaters the most likely explanation is sorption of $\mathrm{Mn}$ to Fe oxides, which are released into solution when Fe is reduced.

Since the occurrence of elevated Mn concentrations is widespread in groundwaters from all aquifer types, consideration should be given to monitoring Mn more widely in both public and private groundwater supplies in Scotland and by implication elsewhere.

Keywords: groundwater, iron, manganese, redox, Scotland, water supplies 


\section{Introduction}

The trace metal manganese $(\mathrm{Mn})$ is ubiquitous in the environment; it is a minor component of most rock types and is also present in soils from weathering and aerial deposition. Mn can exist in different oxidation states, but the most widely occurring forms in the environment are soluble Mn (II) when reduced and insoluble Mn (IV) when oxidised. Naturally occurring Mn is commonly found in drinking water supplies and is essential for human health at low concentrations (Keen and Zidenberg-Cherr, 1994). The World Health Organization (WHO) has set a guideline value of $0.4 \mathrm{mg}^{-1}$ (WHO, 2008): nevertheless, most countries have set a lower limit primarily due to aesthetic and infrastructure problems; e.g. Mn is listed as an indicator parameter by the EC at a concentration of $0.05 \mathrm{mg} \mathrm{l}^{-1}$ in drinking water (EC, 1998).

Excessive Mn concentrations can result in metallic tasting water, staining of clothes, dishes, and products such as paper or plastics, and reduced water pressure and flow in pipes from accumulation of Mn oxides (Sly et al., 1990). Although Mn can be removed from water by treatment (Casale et al., 2002), this is expensive and water supply infrastructure prior to treatment, such as pipes, pumps and boreholes, may still be adversely affected by build up of Mn oxides (Sly et al., 1990). Hence if the occurrence of excessive Mn concentrations can be predicted, it could be avoided when sourcing new water supplies.

Furthermore, several studies in different environmental settings have reported significant associations between exposure to $\mathrm{Mn}$ in groundwater-sourced drinking water supplies and

60 adverse human health effects. For example, Wasserman et al. (2006) identified a significant

61 negative relationship between well water Mn concentration (0.004-3.91 $\left.\mathrm{mg} \mathrm{l}^{-1}\right)$ and measures 
of intellectual function in 142 children of 10 years of age in Bangladesh (notable difference in intellectual function between $<0.2 \mathrm{mg}^{-1}$ group and $>1 \mathrm{mg}^{-1}$ group). Mn exposure associated with drinking water was also significantly positively related with hyperactive classroom behaviours in a study of 46 children in Québec (Bouchard et al., 2007). In adults, exposure to elevated $\mathrm{Mn}$ concentrations in drinking water has been associated with manganism, a Parkinson-like disorder. In a study in Greece (Kondakis et al., 1989), neurological symptoms of chronic Mn poisoning were found to increase with exposure to $\mathrm{Mn}$ from groundwater-sourced water supplies in three populations of adults with similar social and dietary characteristics (concentrations ranging from 0.0036 to $2.3 \mathrm{mg} \mathrm{l}^{-1}$, effects were first noted in a group drinking concentrations 0.08 to $0.25 \mathrm{mg} \mathrm{l}^{-1}$ ). Because of the association between Mn intake and neurological effects, the WHO current guideline concentration for $\mathrm{Mn}$ in drinking water is $0.4 \mathrm{mg} \mathrm{l}^{-1}$ (World Health Organization, 2008), although the USA has a lower health reference level of $0.3 \mathrm{mg} \mathrm{l}^{-1}$ (USEPA, 2003). In the studies by Wasserman et al. (2006) and Kondakis et al. (1989) there was evidence of a dose-response relationship between the severity of neurotoxic effects and exposure to $\mathrm{Mn}$ in well water suggesting that exposure to Mn concentrations below the WHO guideline value could still result in adverse health effects, with children most vulnerable (Ljung and Vahter, 2007). Consequently Bouchard et al. (2007) recommend that further research is required to establish adequate guidelines for $\mathrm{Mn}$ in drinking water.

The occurrence and concentration of $\mathrm{Mn}$ in groundwater is controlled by many factors, the main ones being rock geochemistry, water chemistry and microbiological activity. Some rock types, such as mafic and ultramafic rocks, shale, greywacke and limestone, contain high concentrations of $\mathrm{Mn}$, which can lead to elevated concentrations in soil and sediment through weathering processes. Water chemistry, in particular $\mathrm{pH}$, redox potential (Eh), dissolved 
oxygen (DO), and dissolved organic carbon (DOC), is instrumental in mobilising Mn and controlling its speciation and concentration in the water environment. Manganese occurs mainly as the reduced soluble $\mathrm{Mn}^{2+}$ at lower $\mathrm{pH}$ and $\mathrm{Eh}$, but is oxidised to form precipitates in the presence of oxygen and at higher $\mathrm{pH}(\mathrm{Hem}, 1985)$. Hence in equilibrium conditions $\mathrm{Mn}$ is likely to occur as $\mathrm{Mn}^{2+}$ at $\mathrm{pH}<7$ and at $\mathrm{Eh}$ as high as $800 \mathrm{mV}$. Complexation with humic substances (e.g. Graham et al., 2002) inhibits Mn oxidation and precipitation, although complexation with inorganic ligands, such as sulphate or hydrogen carbonate, is suggested to have only a limited effect on Mn speciation and concentration, apart from at very high ligand concentrations (Hem, 1972). Micro-organisms can play an important role in Mn mobilisation in the environment and can both enhance or inhibit concentrations in groundwater. The effects can be direct, through enzymatic catalysis of Mn oxidation and reduction and specific binding by cell-associated materials, or indirect, by altering the $\mathrm{pH}$ and Eh conditions of the micro-environment, thereby influencing Mn speciation and concentration (Nealson, 1983). The impact of microbiological activity on Mn behaviour in water is frequently evident in the accumulation of oxidised Mn in biofilms on surfaces such as pipes (Sly et al., 1990). The factors described above frequently interact to determine Mn concentrations in groundwater. For example, Bourg and Bertin (1994) and Gounot (1994) attributed spatial and temporal changes in Mn concentrations in two alluvial aquifers in France to different mineralogical forms of Mn and also to the reduction of solid Mn oxides to the dissolved form in anaerobic conditions generated by microbial degradation of organic matter.

There is increasing evidence (Robins, 2002; MacDonald and Ó Dochartaigh, 2005) that Mn is often present in Scottish groundwaters at concentrations in excess of the Scottish drinking water supply limit of $0.05 \mathrm{mg} \mathrm{1}^{-1}$ (as defined by the Water Supply (Water Quality)(Scotland) Act 2001) and may be in excess of the WHO guideline value of $0.4 \mathrm{mg} \mathrm{l}^{-1}$. In Scotland 
112 groundwater is the main source of water for an estimated 30,000 private water supplies and

113 approximately $7 \%$ of public water supplies and is also a major contributor to environmental

114 flows, through baseflow to rivers and streams (MacDonald et al., 2005). Concerns related to

115 excessive Mn concentrations are greatest for private water supplies, which are generally

116 groundwater based, but are not subject to such stringent testing as public water supplies so

117 that elevated concentrations could go unnoticed.

118 The aims of this current research are to assess the concentrations of Mn in Scottish

119 groundwaters, compare between different aquifer types, and examine controls on elevated

120 concentrations in groundwater.

\section{Methods}

124 The first step in the research was to compile a quality-controlled dataset of Mn concentrations and other physicochemical parameters in Scottish groundwaters. Since 2005 considerably more data on Scottish groundwater have become available through the Baseline Scotland

127 project, jointly funded by the British Geological Survey (BGS) and Scottish Environment

128 Protection Agency (SEPA), which is systematically sampling and analysing groundwater

129 from the main hydrogeological units across Scotland (BGS, 2010). Groundwater chemistry

130 data from the Baseline database assembled prior to 2008 for 190 sites in eastern and southern

131 Scotland were used. Collected samples were passed through a $0.45 \mu \mathrm{m}$ filter and acidified to

$1321 \% \mathrm{v} / \mathrm{v}$ with Aristar grade concentrated nitric acid in the field. Samples were analysed by

133 ICP-MS at BGS laboratories in the UK and a commercial laboratory in Canada.

135 Groundwater chemistry data for Scotland collected prior to 2005 in other BGS projects and

136 by other organizations were compiled and reviewed by MacDonald and Ó Dochartaigh 
137 (2005). These datasets had been subject to quality assurance, such as removing samples from

138 highly contaminated sites and samples in which the balance between cations and anions

139 differed by $>10 \%$, and were included in the Mn dataset after further quality control. The

140 criteria for including samples in the Mn dataset were a limit of detection $<0.003 \mathrm{mg} \mathrm{Mn}^{-1}$

141 and use of the same sample preparation procedure as the Baseline samples (i.e. filtration and

142 acidification in the field). The final step in compiling the dataset was to select one set of

143 chemistry data for the $c .100$ sites which had duplicate samples in order to minimise data bias

144 to a particular location or geology type. Where a site had been sampled by more than one

145 organization, following the practice in other studies (Shand et al., 2007) data with better

146 detection limits and a more comprehensive suite of analysis were preferred. $\mathrm{Mn}$

147 concentrations reported as less than a detection limit (only data below $0.003 \mathrm{mg}^{-1}$ ) were

148 given a numerical value of half the detection limit for statistical analysis.

149 The final dataset contained data for Mn in groundwater from 475 sites across Scotland

150 (Figure 1). Data were divided into nine geological categories, based on the principal

151 geological units from which samples were taken (Figure 2). Categories were chosen to enable

152 comparison with previous work on characterising Scottish aquifers (MacDonald and Ó

153 Dochartaigh, 2005) and to contain sufficient numbers of samples for analysis to determine the

154 effect of geology on Mn concentrations. Relationships between Mn and a number of other

155 physicochemical parameters measured in the same samples (where available) which are

156 likely to influence Mn concentrations (Eh, pH, DO, DOC, specific electrical conductance

157 (SEC), $\mathrm{HCO}_{3}, \mathrm{NO}_{3}-\mathrm{N}, \mathrm{Fe}, \mathrm{Ca}, \mathrm{Mg}$ ) were examined using scatter plots and multiple linear

158 regression to assess the effect of water chemistry on Mn concentrations. Mn and Fe

159 concentrations were $\log _{10}$-transformed for the regression analyses, conducted in Minitab v.15,

160 in order to normalise the data distributions. $\mathrm{P}$ values were used to test significance at $95 \%$

161 probability. 


\section{Results}

164

\subsection{Analysis of the complete dataset of Mn concentrations in Scottish groundwaters}

166 Mn concentrations in Scottish groundwaters are log-normally distributed, with the lower end

167 of the distribution affected by samples with concentrations below the limits of detection

168 (Figure 3). The median Mn concentration was $0.013 \mathrm{mg}^{-1}$, but there was a wide variation in

169 Mn concentrations and $25^{\text {th }}$ and $75^{\text {th }}$ percentiles were $0.0014 \mathrm{mg} \mathrm{l}^{-1}$ and $0.072 \mathrm{mg} \mathrm{l}^{-1}$,

170 respectively. The Scottish limit for $\mathrm{Mn}$ in drinking water of $0.05 \mathrm{mg}^{-1}$ was exceeded in $30 \%$

171 of samples; the WHO health guideline (WHO, 2008) of $0.4 \mathrm{mg} \mathrm{l}^{-1}$ was exceeded in $9 \%$, and

172 the USEPA limit (USEPA, 2003) of $0.3 \mathrm{mg} \mathrm{l}^{-1}$ exceeded in $12 \%$.

174 Similar distributions of Mn concentrations in groundwater used for drinking water have been reported elsewhere. In Sweden, the median Mn concentration in 12,000 sampled wells was

$1760.06 \mathrm{mg} \mathrm{l}^{-1}$ and around $20 \%$ of wells exceeded the Swedish recommended guideline value for 177 private wells of $0.3 \mathrm{mg}^{-1}$ (Ljung and Vahter, 2007). In a survey of 2160 private wells in the

178 USA used for household drinking water (DeSimone, 2008), 5\% of those tested had Mn

179 concentrations greater than the health reference level $\left(0.4 \mathrm{mg} \mathrm{l}^{-1}\right)$ and $21 \%$ had concentrations 180 in excess of the USEPA Secondary Maximum Contaminant Level set for aesthetic quality 181 and other non-health reasons $\left(0.05 \mathrm{mg} \mathrm{l}^{-1}\right)$. In a survey of total Mn (i.e. not filtered) from

18210,000 groundwater sources in New Zealand, Daughney (2003) found that 39\% exceeded $1830.05 \mathrm{mg} \mathrm{l}^{-1}$ and $15 \%$ exceeded the New Zealand health guideline of $0.5 \mathrm{mg}^{-1}$.

185 Figure 1 shows the spatial distribution of groundwater Mn concentrations and Figure 2 the 186 bedrock aquifer units in Scotland. Mn concentrations in groundwater varied widely across 
187 Scotland and also locally. Many groundwater samples from Moray, Aberdeenshire, the

188 Central Belt and Dumfries and Galloway contained excessive Mn concentrations. In contrast, 189 generally low Mn concentrations occurred in groundwater samples from the Strathmore area

190 and much of southern Scotland. Mn concentrations also varied within and between rock types

191 from which groundwater samples were taken (Figure 4). The Scottish drinking water limit

192 was exceeded by some groundwater samples from all geological categories and lay within the interquartile range $\left(25^{\text {th }}-75^{\text {th }}\right.$ percentiles, the lower and upper limits of the boxes in Figure 4) in the Superficial, Permian/Triassic/Jurassic and most notably in the Carboniferous and Northern Devonian categories. Mn concentrations in groundwater samples varied by at least

196 three orders of magnitude within each geological category emphasising that it is not possible

197 to predict from rock type alone whether groundwater might have elevated $\mathrm{Mn}$.

198 Multiple linear regression of 10 other physicochemical parameters with Mn concentration for the 119 samples for which all these data were available showed that Mn was significantly inversely related to $\mathrm{pH}$, Eh and DO and significantly positively related to Fe (Table 1). Together these parameters explained $50 \%$ of the variance in Mn concentrations. When

$202 \log _{10} \mathrm{Fe}$ was not included, $42 \%$ of the variance was explained and the strength of the

203 relationship with $\mathrm{pH}$ and Eh increased. Since $\mathrm{Mn}$ and Fe are often closely related in natural waters (Collins and Buol, 1970; Hem, 1985; DeSimone, 2008), the controls on Fe concentrations in Scottish groundwaters were investigated by repeating the multiple regressions with $\mathrm{Fe}$ as the dependent variable (Table 1). Although $\log _{10} \mathrm{Mn}$ concentrations

207 were significantly related to $\log _{10} \mathrm{Fe}$, when this predictor was excluded, the parameters

208 significantly related to Fe were Eh (negatively), DOC and SEC (positively), suggesting that 209 Mn and Fe concentrations in groundwater are affected by rather different physicochemical 210 conditions. 


\section{$212 \quad 3.2 \quad$ Analysis of data for the Devonian sedimentary aquifer}

213 Multiple regression analyses of the complete dataset helped to identify overall

214 physicochemical influences on $\mathrm{Mn}$ and Fe concentrations in groundwater across a range of

215 rock types, but the patterns observed may also be affected by variation in rock geochemistry,

216 which may account for some of the unexplained variance. However, whole rock

217 geochemistry data are not widely available for groundwater sampling sites in Scotland, so

218 further analysis including rock geochemistry is not currently possible. Therefore, in order to

219 assess in more detail the physicochemical controls on Mn concentrations in groundwater,

220 data for one aquifer type (Devonian sedimentary rocks) were further interpreted, to minimise

221 large variations in manganese rock geochemistry (BGS, 2009). Devonian aquifers are widespread in Scotland and provide a valuable groundwater resource (Graham et al., 2009). Samples were available for Devonian aquifers in three geographical locations: Northern

Devonian (north of Aberdeen), Strathmore Devonian (between Aberdeen and the Firth of Tay) and Southern Devonian (south of the Firth of Tay).

For the Devonian dataset, multiple linear regression analyses to predict $\mathrm{Mn}$ and $\mathrm{Fe}$ concentrations with different numbers of predictors (Table 2) showed broadly similar relationships as for the total dataset. The same physicochemical parameters ( $\mathrm{pH}, \mathrm{Eh}$ and DO) were significantly related to Mn concentrations but for the Devonian samples there was no observable independent relationship with $\mathrm{Fe}$. These three parameters alone explained $58 \%$ of the variance (compared with only $42 \%$ of the variance for the total dataset explained by $\mathrm{pH}$, Eh, DO and an additional 6 parameters (Table 1)). Eh was the strongest independent predictor (see Table 2 and Figure 5) followed by $\mathrm{pH}$ and DO. Iron concentrations in the complete dataset but there was no significant relationship of Fe with Mn or SEC (Table 2). 


\section{Discussion}

240 The analysis of groundwater chemistry data has shown that undesirable Mn concentrations

241 are a problem in Scotland's groundwater, with the Scottish drinking water limit being exceeded at $30 \%$ of the 475 sites sampled, and the WHO health guideline limit being exceeded at $9 \%$ of the sites. Mn concentrations were significantly negatively correlated to the redox and $\mathrm{pH}$ conditions of the water. Excessive Mn concentrations occurred particularly in groundwater from the Northern Devonian, Carboniferous and Superficial geological categories, although high concentrations were measured in samples from all geological categories.

\subsection{Geology as a control on Mn concentrations}

250 The variation in groundwater Mn concentrations between and within different geological

251 categories may be caused both by differences in the concentration and nature of Mn present

252 in the aquifer rocks and also the physicochemical conditions within the aquifer. There are insufficient rock chemistry data to be able to test this hypothesis robustly; however, the broad data distribution suggests that the water chemistry conditions are more significant than $\mathrm{Mn}$ mineralogy. There is considerably more variability in Mn concentrations within aquifer types

256 than between them (Figure 4) and this variability is largely explained by redox and $\mathrm{pH}$

257 conditions.

\section{2 $\mathrm{pH}$ and redox conditions as controls on Mn concentrations}

260 The significant influence of $\mathrm{pH}$ and redox conditions on Mn concentrations in Scottish

261 groundwaters was further investigated by plotting the Mn concentrations measured in 
262 Scottish groundwaters on a predominance diagram (Figure 6). This diagram illustrates that

$263 \mathrm{Mn}^{2+}$ can be mobilised over a large range of Eh and $\mathrm{pH}$ values. All of the Scottish data above

264 detection limit plot within the $\mathrm{Mn}^{2+}$ area of the predominance diagram as would be expected.

265 However, some samples have low Mn concentrations even in conditions where $\mathrm{Mn}^{2+}$ can be

266 mobilised, indicating that redox and $\mathrm{pH}$ conditions do not totally explain manganese

267 distributions in groundwater.

268 The predominance diagrams for Mn suggest a stronger influence of $\mathrm{pH}$ on $\mathrm{Mn}$ mobilisation

269 than Eh, since there is a greater gradient of $\mathrm{Mn}^{2+}$ concentration change in relation to $\mathrm{pH}$ than

270 Eh. However, this pattern is not apparent in either the total dataset or the Devonian subset,

271 where Eh was a much stronger predictor of $\mathrm{Mn}^{2+}$ concentrations than $\mathrm{pH}$ (Table 1 and

272 Figure 5). This discrepancy may exist because at the near neutral $\mathrm{pH}$ of most Scottish

273 groundwater, $\mathrm{Mn}^{2+}$ concentrations may be influenced by other factors such as complexation

274 with bicarbonate and sulphate ions if they are present at high concentration (Hem, 1972) or

275 interaction with Fe (Collins and Buol, 1970).

$277 \quad 4.3 \quad$ Fe as a control on Mn concentrations

278 Multiple linear regression analysis of the complete dataset showed that the water chemistry

279 parameter most strongly related (along with dissolved oxygen) to Mn concentrations in

280 Scottish groundwaters was Fe. However, the relationship between Mn and Fe concentrations

281 is not linear (Figure 7). The scatterplot of concentrations of the two elements showed that

282 high Fe concentrations only occur with high Mn concentrations, but high Mn concentrations 283 occur across the range of $\mathrm{Fe}$ concentrations. The regression analyses for predicting $\mathrm{Mn}$ and

284 Fe separately using the complete dataset provided further evidence that the two elements do 285 not behave in exactly the same way in Scottish groundwaters, since Mn concentrations were

286 significantly related to $\mathrm{Eh}, \mathrm{DO}$ and $\mathrm{pH}$, and $\mathrm{Fe}$ to DOC and $\mathrm{SEC}$ in addition to Eh. The 
significant relationship of both $\mathrm{Mn}$ and Fe with Eh suggests that interaction between the two elements in groundwater is mediated by Eh.

There is a close relationship between $\mathrm{Mn}$ and $\mathrm{Fe}$ oxidation and reduction in natural waters beyond the common redox conditions required for mobilisation (Marshall, 1979; Lind et al. 1987; Thamdrup 2000). Since $\mathrm{Mn}^{2+}$ has a high affinity for ferric oxides, the precipitation of Fe oxides at lower Eh than Mn may lead to the removal of Mn by occlusion and sorption to precipitated Fe (Morgan and Stumm, 1965;Collins and Buol, 1970). Therefore, in solutions containing both $\mathrm{Mn}$ and Fe, such as Scottish groundwaters, which are not strongly reducing and are circumneutral, $\mathrm{Mn}^{2+}$ concentrations may be lower than expected at a particular Eh. Conversely, when Fe oxides are reduced, $\mathrm{Mn}^{2+}$ is released. Along with the occurrence of $\mathrm{pH}$ and Eh conditions which result in both $\mathrm{Mn}$ and Fe mobilisation, this process may also explain why high Fe concentrations often occur with high Mn concentrations in Scottish groundwater. An additional complication is that $\mathrm{Fe}^{2+}$ is more likely to adsorb or form complexes with DOC than Mn, resulting in higher $\mathrm{Fe}^{2+}$ concentrations occurring than expected at a particular Eh (Hem, 1972).

\subsection{Implications for groundwater monitoring}

The research results have particular implications for monitoring of private water supplies in Scotland, which are often groundwater based. Water quality standards for private supplies in Scotland are derived from EC regulation, and monitoring and protection is carried out by local authorities. The level of monitoring depends on whether a private water supply is classified as Type A (providing $10 \mathrm{~m}^{3}$ or more per day, supplying 50 or more people, or used for commercial or public activity) or Type B supplies (all others) (Astron, 2006). Chemical parameters are tested for in both types of supply, but Type A supplies are subject to more 
312 regular and stringent testing and enforcement of water quality regulations than Type $\mathrm{B}$, which

313 are only monitored on a discretionary basis (Donnelley, 2008). Therefore, Mn may not be

314 tested and high concentrations can go undetected.

316 Another major issue is sampling protocol. Samples collected for routine monitoring carried

317 out by the regulatory bodies are often not filtered or acidified in the field, giving unreliable

318 Mn data. In creating the dataset used for this Scottish study, a comparison was undertaken

319 between samples collected with good and poor protocol for 40 locations. For samples with

320 poor field protocol Mn concentrations were consistently underestimated by more than an

321 order of magnitude. In addition, for a reliable measure of exposure to Mn for public health

322 reasons, samples would need to be taken throughout the year to capture natural variations.

323 The range of Mn concentrations encountered in each geological unit also has implications for

324 groundwater monitoring. Manganese concentrations in excess of the Scottish limit of 0.05

$325 \mathrm{mg} \mathrm{l}^{-1}$ and the WHO health guideline value of $0.4 \mathrm{mg} \mathrm{l}^{-1}$ were found in each aquifer unit, and

326 there was more variability within each unit than between them. Therefore, developing hazard

327 maps identifying areas of potential elevated Mn concentrations from geology alone are

328 unlikely to be effective. Monitoring therefore needs to be widespread.

330 Based on the discussion above, more widespread testing of Scottish private water supplies

331 using appropriate sampling protocols is required to give greater confidence in the $\mathrm{Mn}$

332 concentrations in private water supplies in Scotland. These recommendations have relevance

333 elsewhere. Although studies in other countries have reported elevated Mn concentrations in

334 groundwater-sourced drinking water supplies, monitoring of drinking water supplies for Mn

335 is not routine. 


\section{Conclusion}

338

339 This research developed a quality-controlled dataset of groundwater Mn concentrations

340 across Scotland for 475 sites, which forms the basis of the analysis in this paper, and can

341 serve as a resource for future research into Mn occurrence in Scottish groundwaters. Analysis

342 of this dataset showed that elevated Mn concentrations $\left(>0.05 \mathrm{mg} \mathrm{l}^{-1}\right)$ occurred in $30 \%$ of the

343 Scottish groundwater sites sampled, particularly in Superficial, Carboniferous, and Northern

344 Devonian aquifers; and 9\% of sites had concentrations above the WHO health drinking water

345 limit $\left(0.4 \mathrm{mg} \mathrm{l}^{-1}\right)$. The principal controls on Mn concentrations in groundwater in Scotland are

346 redox conditions and $\mathrm{pH}$, with some influence of Fe behaviour. Redox conditions exercise

347 the strongest control. The scale of the problem of excessive Mn concentrations in

348 groundwater across all aquifer types highlights the need for wider sampling for Mn in private

349 water supplies in Scotland, and by implication, worldwide.

\section{Acknowledgements}

352

353

The research was jointly funded by the British Geological Survey (BGS) and the School of

354 GeoSciences, The University of Edinburgh. The authors are grateful to BGS/SEPA for access to groundwater data and to the following BGS staff for help and comments: Derek

Ball, Fiona Fordyce, Martin Gillespie, David Kinniburgh, Pauline Smedley and Stuart

Horsburgh. This paper is published with permission of the Executive Director of the British 


\section{References}

362

363

Astron. Private Water Supplies: Technical Manual. Scottish Executive, Edinburgh, 2006.

BGS. Manganese in stream sediments: Great Britain. G-BASE Geochemical Map. Keyworth, Nottingham, UK, 2009.

BGS. Baseline Scotland: groundwater chemistry data. British Geological Survey http://www.bgs.ac.uk/data/baselineScotland/home.html [accessed online on 1 February 2010]

Bouchard M, Laforest F, Vandelac L, Bellinger D, Mergler D. Hair manganese and hyperactive behaviours: pilot study of school age children exposed through tap water. Environ Health Persp 2007; 115: 122-127.

Bourg ACM, Bertin C. Seasonal and spatial trends in manganese solubility in an alluvial aquifer. Environ Sci Technol 1994; 28: 868-876.

Casale RJ, LeChevallier MW, Pontius FW. Review of manganese control and related manganese issues. American Water Works Association (AWWA) Research Foundation and AWWA, Denver, 2002.

Collins JF, Buol SW. Effects of fluctuations in the Eh-pH environment on iron and/or manganese equilibria. Soil Sci 1970; 110: 111-118.

DeSimone LA. Quality of water from domestic wells in principal aquifers of the United States, 1991-2004: US Geological Survey Scientific Investigations Report 2008-5227, 139 p., 2008.

Donnelley RR. Drinking Water Quality in Scotland 2007. Drinking Water Quality Regulator for Scotland, 2008. human consumption. Official Journal 1998; L330: 32-54. 
Gounot, A-M. Microbial oxidation and reduction of manganese: Consequences in groundwater and applications. FEMS Microbiol Rev 1994; 14: 339-350.

Graham MC, Gavin KG, Farmer JG, Kirika A, Britton A. Processes controlling the retention and release of manganese in the organic rich catchment of Loch Bradan. Appl Geochem 2002; 17: 1061-1067.

Graham MT, Ó Dochartaigh BÉ, Ball DF, MacDonald AM. Using transmissivity, specific capacity and borehole yield data to assess the productivity of Scottish aquifers. Quarterly Journal of Engineering Geology and Hydrogeology 2009; 42: 227-235

Hem JD. Chemical factors that influence the availability of iron and manganese in aqueous systems. Geol Soc Am Bull 1972; 83: 443-450.

Hem JD. Study and Interpretation of the Chemical Characteristics of Natural Water $\left(3^{\text {rd }}\right.$ Ed.). US Geological Survey Water-Supply Paper 2254, 1985.

Keen CL, Zidenberg-Cherr S. Manganese toxicity in humans and experimental animals. In: Klimis-Tavantzis DJ, editor. Manganese in Health and Disease. CRC Press, London, 1994, pp. 193-205.

Kondakis XG, Makris N, Leotsinidis M, Prinou M, Papapetropoulos T. Possible health effects of high manganese concentrations in drinking water. Arch Environ Health 1989; 44: 175-178.

Lind CJ, Hem JD, Roberson CE. Reaction products of manganese bearing waters In: Averett, RC, McKnight DM, editors. Chemical Quality of Water and the Hydrologic Cycle. Lewis Publishers, Michigan, USA, 1987, pp. 271-302.

Ljung K, Vahter M. Time to re-evaluate the guideline value for manganese in drinking water? Environ Health Persp 2007; 115: 1533-1538. 
MacDonald A, Ó Dochartaigh BÉ Baseline Scotland; an overview of available groundwater chemistry data for Scotland. British Geological Survey Commissioned Report, CR/05/239N. British Geological Survey, Keyworth, Nottingham, 2005.

MacDonald A, Robins NS, Ball DF, Ó Dochartaigh BÉ. An overview of groundwater in Scotland. Scot J Geol 2005; 41: 3-11.

Marshall KC. Biogeochemistry of manganese minerals. In: Trudinger PA, Swaine DJ, editors. Biogeochemical Cycling of Mineral-Forming Elements. Elsevier/North Holland Publishing Co., 1979, pp. 253-286.

Morgan JJ, Stumm W. The role of multivalent metal oxides in limnological transformations, as exemplified by iron and manganese. In: Jaag O, editor. Advances in Water Pollution Research. Proceedings of the Second International Conference, August 1964, Tokyo. Pergamon Press, 1965; 1: 103-131.

Nealson KH. Microbial cycle of manganese. In: Krumbein WE, editor. Microbial Geochemistry. Blackwell, Oxford, 1983, pp. 191-221.

Robins NS. Groundwater quality in Scotland: major ion chemistry of the key groundwater bodies. Sci Total Environ 2002; 294: 41-56.

Shand P, Edmunds WM, Lawrence AR, Smedley PL, Burke S. The natural (baseline) quality of groundwater in England and Wales. British Geological Survey Research Report RR/07/06. British Geological Survey, Keyworth, Nottingham, 2007.

Sly LJ, Hodgkinson MC, Arunpairojana V. Deposition of manganese in a drinking water distribution system. Appl Environ Microbiol 1990; 56: 628-639.

Thamdrup B. Microbial manganese and iron reduction in aquatic sediments. Advances in Microbial Ecology 2000; 16:41-84

USEPA. Health Effects Support Document for Manganese. EPA 822-R-03-003. US Environmental Protection Agency, Washington, DC, 2003. 
434 Wasserman GA, Liu X, Parvez F, Ahsan H, Levy D, Factor-Litvak P, Kline J, van Geen A, Slavkovich V, LoIacono NJ, Cheng Z, Zheng Y, Graziano JH. Water manganese exposure and children's intellectual function in Araihazar, Bangladesh. Environ Health Persp 2006; 114: 124-129.

438 World Health Organization. Guidelines for Drinking-water Quality $\left(3^{\text {rd }}\right.$ Ed incorporating the $1^{\text {st }}$ and $2^{\text {nd }}$ Addenda), Volume 1 recommendations. World Health Organisation, Geneva, 2008, available online at http://www.who.int/water_sanitation_health/dwq/gdwq3rev/en/[accessed 19 August 2009]. 
Table $1 \mathrm{P}$ values for multiple linear regression analysis of Scottish dataset for $\log _{10} \mathrm{Mn}$ and $\log _{10} \mathrm{Fe}$ vs. selected physicochemical parameters. The sign in parentheses after each $\mathrm{P}$ value indicates whether the predictor was positively $(+)$ or negatively $(-)$ related. $\mathrm{P}$ numbers in bold indicate significance at $95 \%$ probability.

\begin{tabular}{|c|c|c|c|c|}
\hline & \multicolumn{2}{|c|}{ Predicting $\log _{10} M n$} & \multicolumn{2}{|c|}{ Predicting $\log _{10} \mathrm{Fe}$} \\
\hline & Incl. Fe & Excl. Fe & Incl. $M n$ & Excl. $M n$ \\
\hline $\mathrm{pH}$ & $0.001(-)$ & $<0.001(-)$ & $0.855(+)$ & $0.146(+)$ \\
\hline $\mathrm{Eh}$ & $0.022(-)$ & $<0.001(-)$ & $0.001(-)$ & $<0.001(-)$ \\
\hline DO & $<0.001(-)$ & $<0.001(-)$ & $0.152(+)$ & $0.220(+)$ \\
\hline SEC & $0.638(+)$ & $0.169(+)$ & $0.066(+)$ & $0.011(+)$ \\
\hline DOC & $0.187(+)$ & $0.060(+)$ & $0.105(+)$ & $<0.001(+)$ \\
\hline $\mathrm{HCO}_{3}$ & $0.852(+)$ & $0.518(+)$ & $0.452(+)$ & $0.223(+)$ \\
\hline $\mathrm{Ca}$ & $0.528(+)$ & $0.610(+)$ & $0.703(-)$ & $0.678(-)$ \\
\hline $\mathrm{Mg}$ & $0.428(-)$ & $0.214(-)$ & $0.286(-)$ & $0.051(-)$ \\
\hline $\mathrm{NO}_{3}-\mathrm{N}$ & $0.331(-)$ & $0.096(-)$ & $0.214(-)$ & $0.222(-)$ \\
\hline $\log _{10} \mathrm{Fe}$ & $<0.001(+)$ & --- & --- & --- \\
\hline $\log _{10} \mathrm{Mn}$ & --- & --- & $0.000(+)$ & --- \\
\hline Number of samples & 119 & 129 & 119 & 125 \\
\hline \multicolumn{5}{|l|}{$\mathrm{R}^{2}$ Adjusted for } \\
\hline sample size & $50 \%$ & $42 \%$ & $45 \%$ & $41 \%$ \\
\hline
\end{tabular}


452 Table $2 \mathrm{P}$ values for multiple linear regression analysis of the Devonian groundwater

453

454

455

456 samples for $\log _{10} \mathrm{Mn}$ and $\log _{10} \mathrm{Fe}$ vs. selected physicochemical parameters. The sign in parentheses after each $\mathrm{P}$ value indicates whether the predictor was positively $(+)$ or negatively (-) related. P numbers in bold indicate significance at 95\% probability.

\begin{tabular}{|c|c|c|c|c|}
\hline & \multicolumn{2}{|c|}{ Predicting $\log _{10} M n$} & \multicolumn{2}{|c|}{ Predicting $\log _{10} \mathrm{Fe}$} \\
\hline & 4 predictors & Excl. Fe & 6 predictors & Excl. $M n$ \\
\hline $\mathrm{pH}$ & $0.011(-)$ & $0.005(-)$ & $0.563(+)$ & $0.961(+)$ \\
\hline Eh & $0.001(-)$ & $<0.001(-)$ & $0.011(-)$ & $<0.001(-)$ \\
\hline DO & $0.037(-)$ & $0.036(-)$ & $0.999(-)$ & $0.608(-)$ \\
\hline SEC & --- & --- & $0.286(+)$ & --- \\
\hline DOC & --- & --- & $0.047(+)$ & $0.007(+)$ \\
\hline $\log _{10} \mathrm{Fe}$ & $0.077(+)$ & --- & --- & --- \\
\hline $\log _{10} \mathrm{Mn}$ & --- & --- & $0.322(+)$ & --- \\
\hline Number of samples & 59 & 62 & 34 & 41 \\
\hline $\begin{array}{l}\mathrm{R}^{2} \text { Adjusted for } \\
\text { sample size }\end{array}$ & $61 \%$ & $58 \%$ & $53 \%$ & $58 \%$ \\
\hline
\end{tabular}




\section{Figure Captions}

460

461 Figure 1 The location of groundwater sites in Scotland sampled for manganese to an 462 appropriate standard.

463 Figure 2 Bedrock aquifer units in Scotland (from MacDonald et al., 2005; Graham et al., 2009).

Figure 3

Cumulative frequency plot for Mn groundwater concentrations for the Scottish dataset $(n=475)$.

Figure 4. Box plot of Mn concentrations, divided into the main different aquifer units in 468 Scotland

469 Figure 5 The relation between Mn concentrations, Eh and $\mathrm{pH}$ for groundwater samples from the Devonian sedimentary aquifer. Eh exhibits the largest control.

471 Figure 6 Data plotted on a predominance diagram for Mn speciation (Hem 1985, PhreeqC)

473 Figure 7 Scatter plot of Mn versus Fe concentrations for the Scottish dataset $(\mathrm{n}=195$, 474 adjusted $\mathrm{R}^{2}=0.25$ ) 


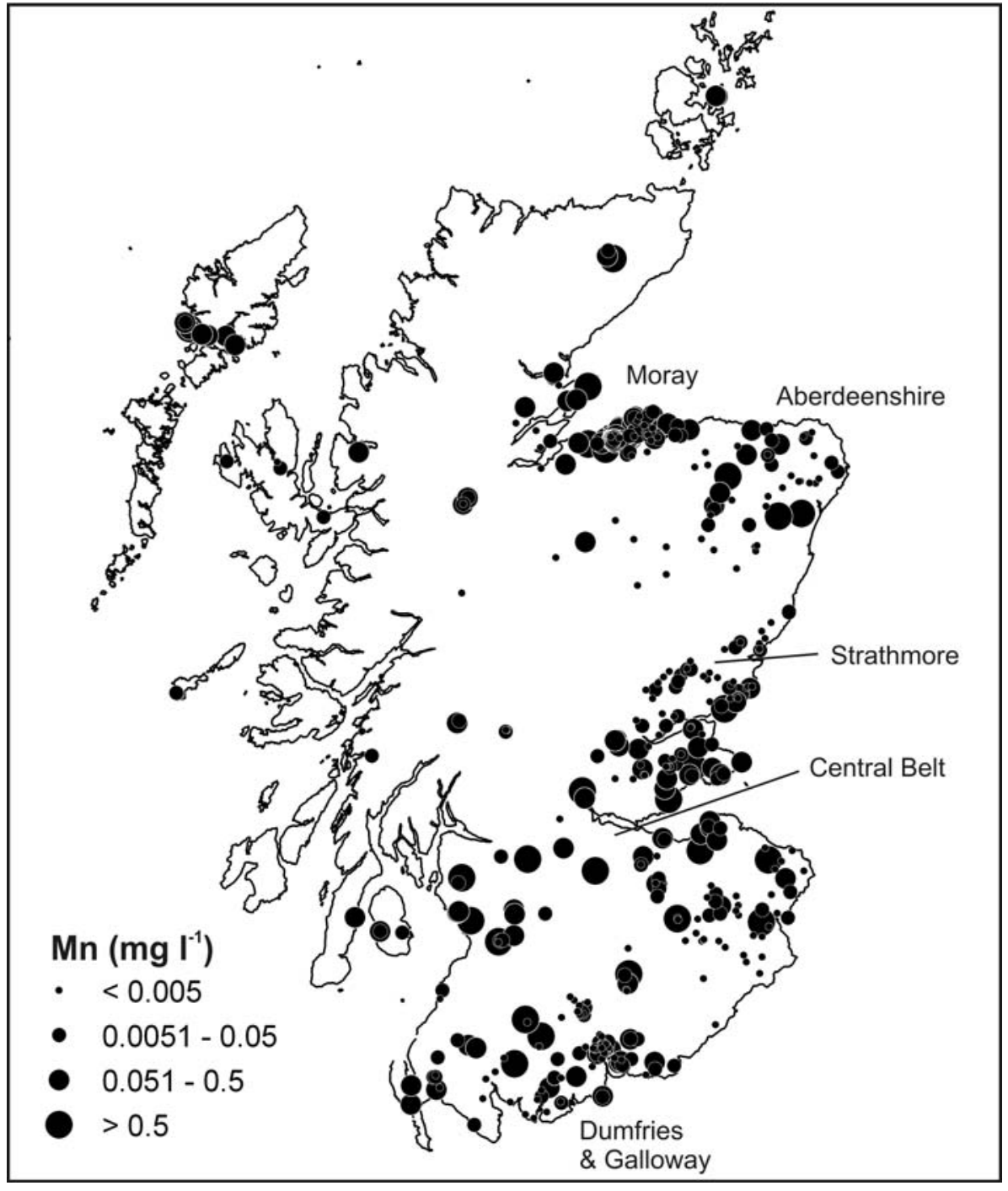

$476 \quad$ Figure 1

477 


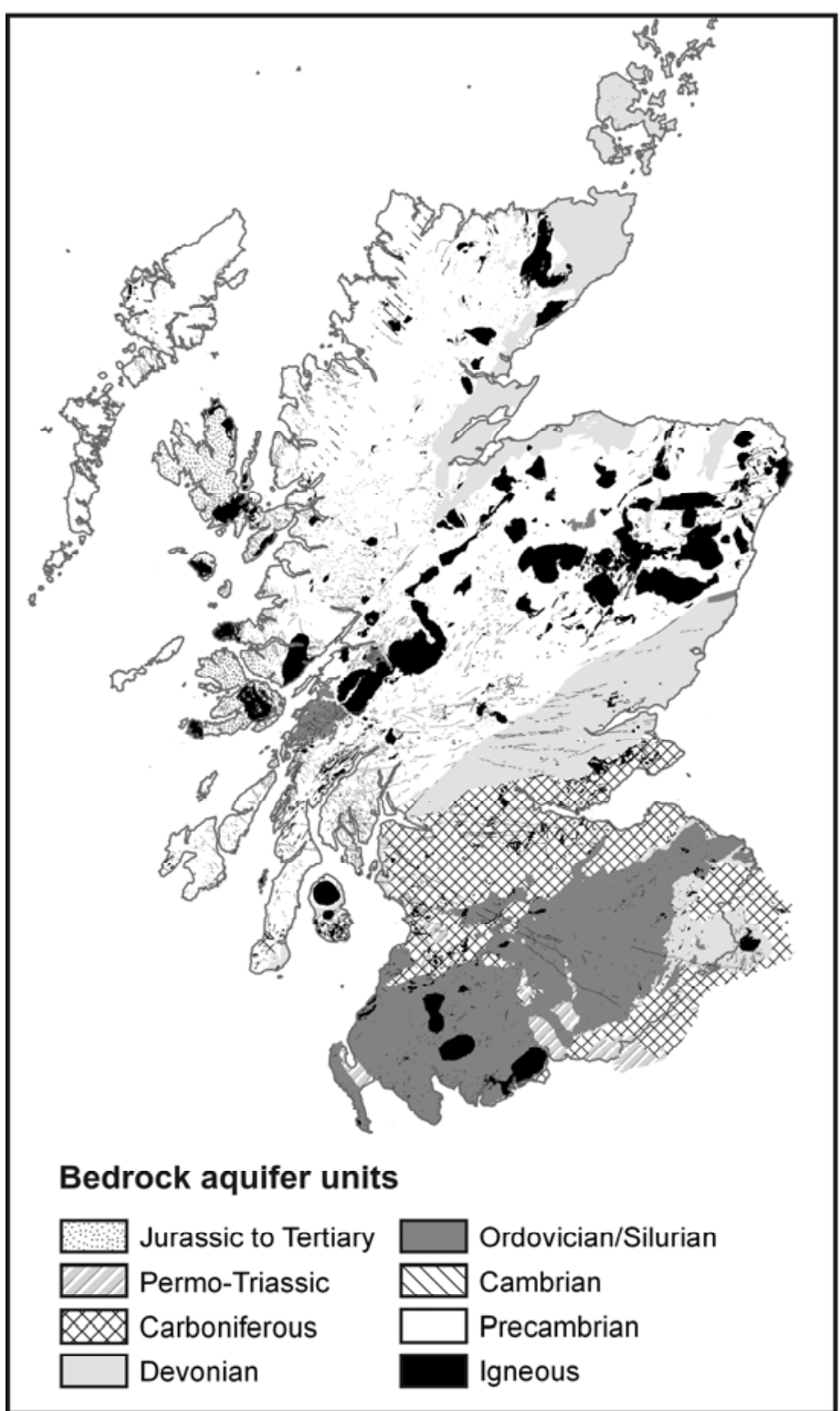

478

Figure 2

480 


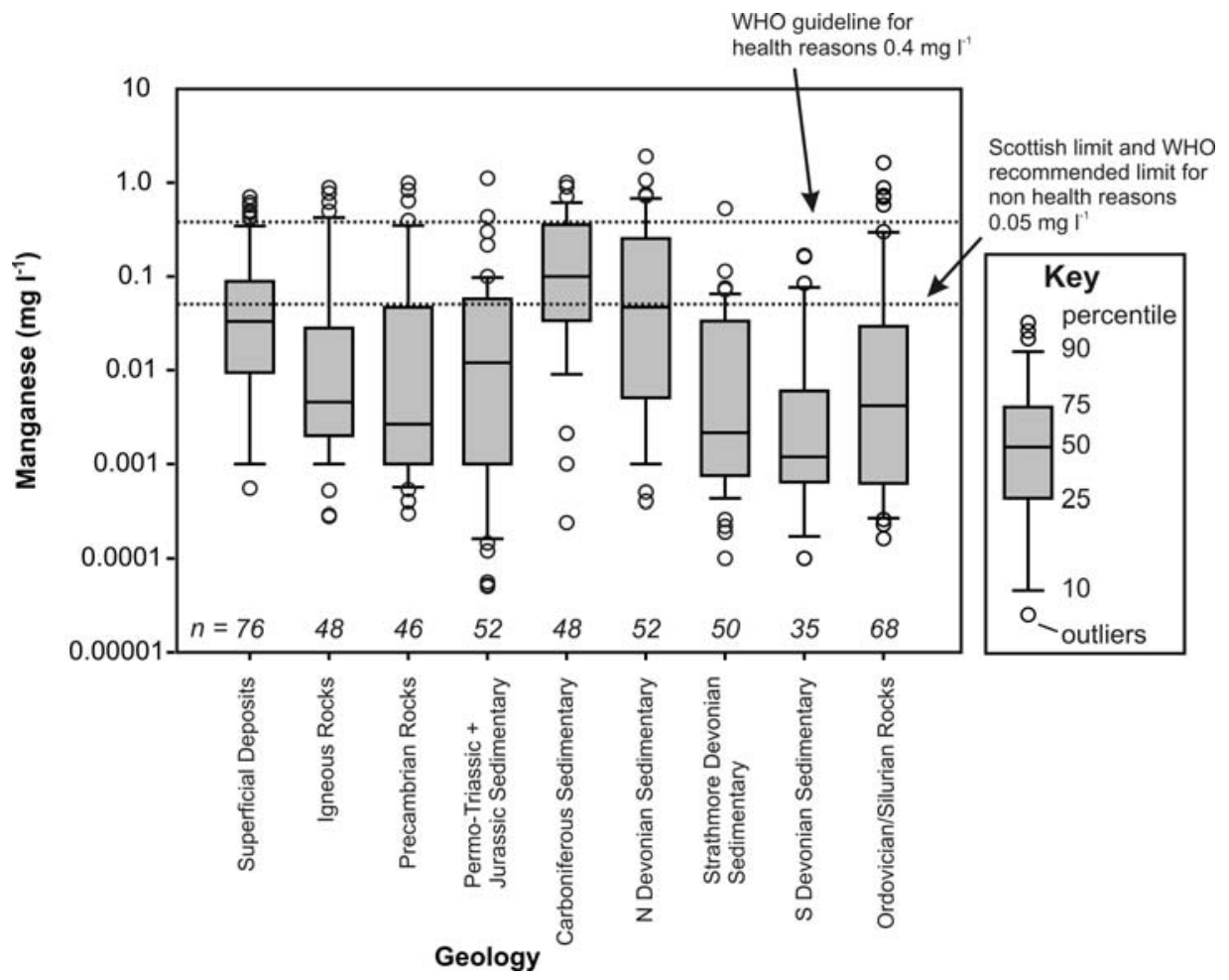

$482 \quad$ Figure 3

483

484

485

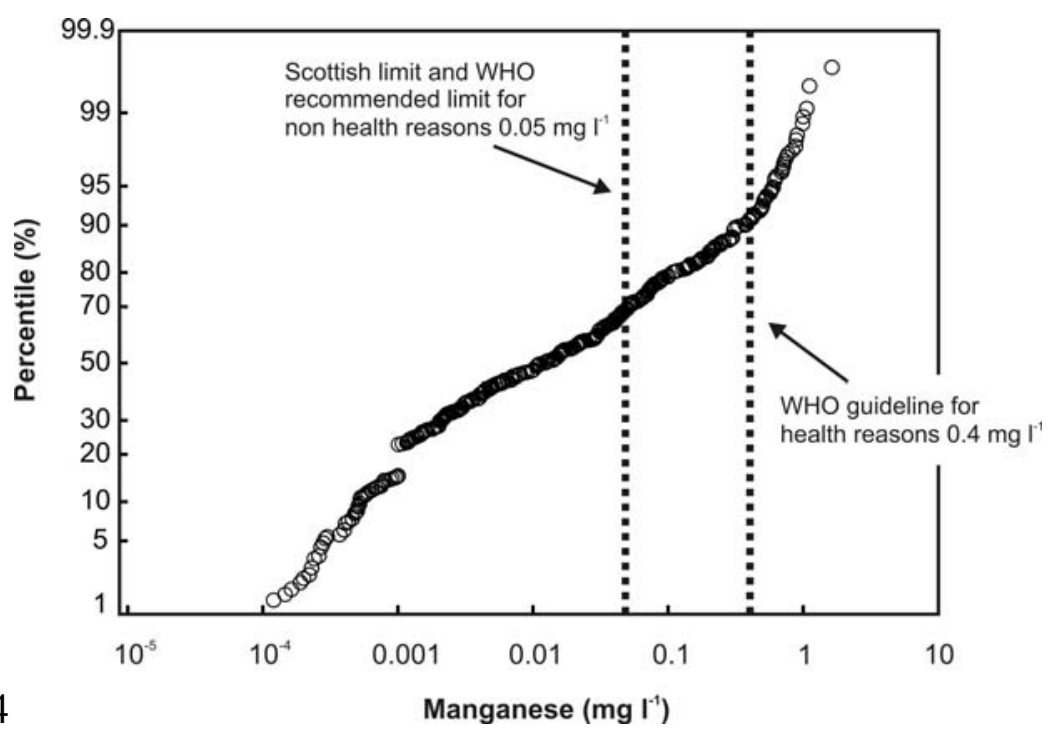

487 


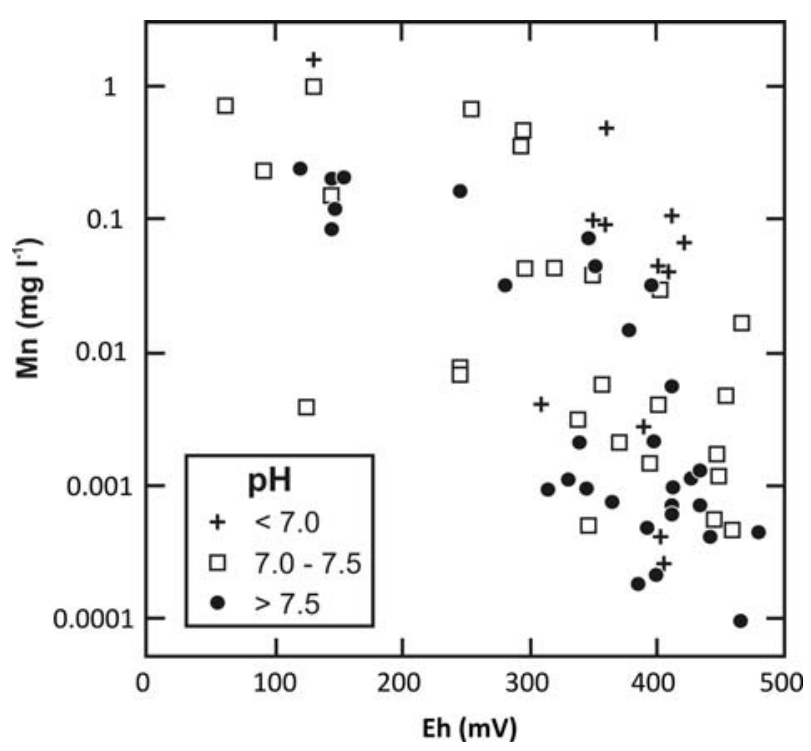

$489 \quad$ Figure 5

490

491

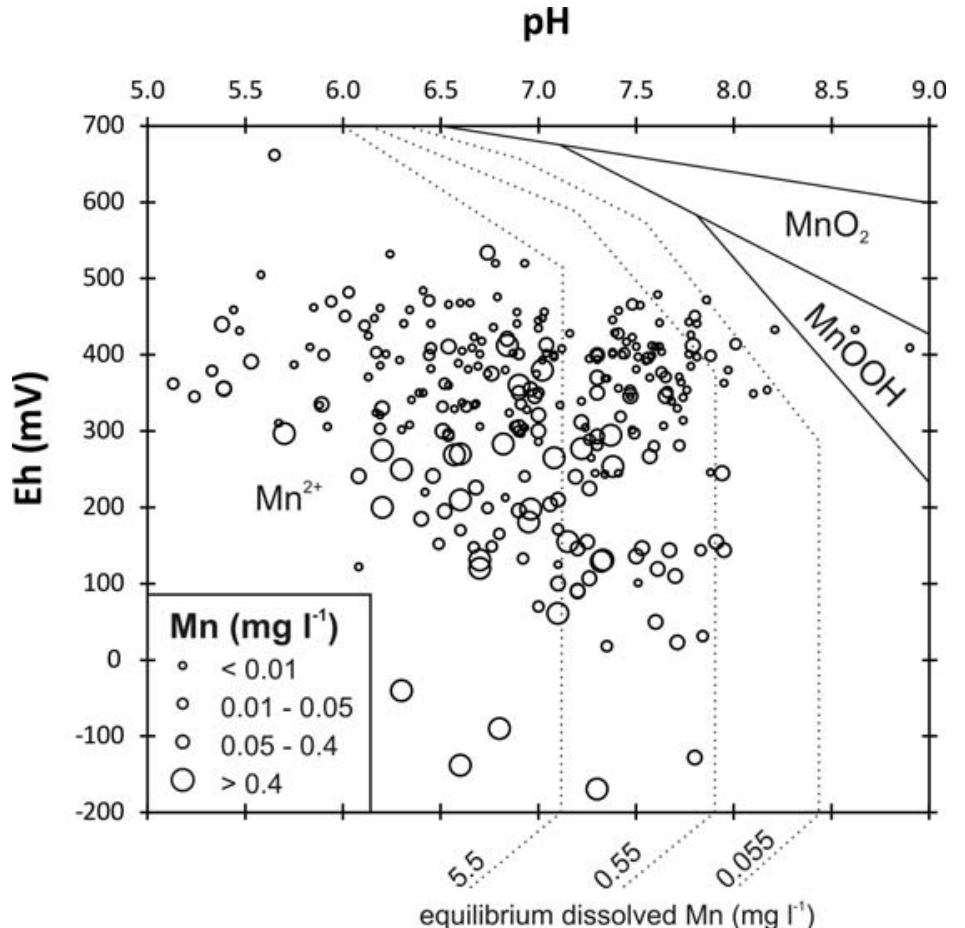

$492 \quad$ Figure 6

493 
494

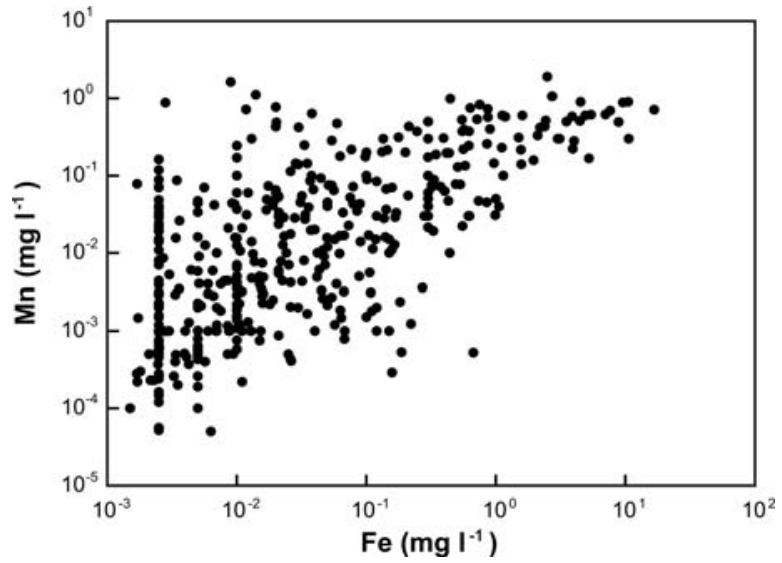

$495 \quad$ Figure 7

496 